\title{
Influencing Factors for the Intercultural Collaboration between Colleagues of an International Enterprise
}

\author{
Petia Genkova ${ }^{1}$ \& Annekathrin Richter ${ }^{2}$ \\ ${ }^{1}$ Department of Business Psychology, Faculty of Social and Economic Sciences, Osnabrück University of \\ Applied Sciences, Germany \\ ${ }^{2}$ University of Passau, Passau, Germany \\ Correspondence: Petia Genkova, Department of Business Psychology, Faculty of Social and Economic Sciences, \\ Osnabrück University of Applied Sciences, 49076 Osnabrück, Germany. Tel: 0541-969-3772. E-mail: \\ p.genkova@hs-osnabrueck.de
}

Received: October 3, 2015

Accepted: October 23, $2015 \quad$ Online Published: November 25, 2015

doi:10.5539/ijbm.v10n12p32

URL: http://dx.doi.org/10.5539/ijbm.v10n12p32

\begin{abstract}
In the study at hand, country- and organization-related cultural influence factors for the collaboration between colleagues of an internationally acting enterprise are empirically investigated. Problem-focused interviews with 26 probands have been conducted to validate the relevance of the researched influencing factors. The hypotheses have been tested with the help of a quantitative measuring instrument (standardized online survey). Findings indicate, that cultural differences on the country-related and organizational level between German and Singaporean colleagues are indeed greater than between German and American employees. These do not lead to a worse intercultural collaboration. Positive effects for the intercultural collaboration could be proven for the scales of collectivism, outcome- and career-orientation, employee-orientation and work climate. Furthermore, higher shaped collectivism, as well as a higher success- and career-orientation could be proven as indicators for the greater success of the German-Singaporean collaboration.
\end{abstract}

Keywords: country culture, organizational culture, intercultural collaboration, influence factors, globalization

\section{Introduction and Problem}

In context of proceeding globalization, it can be observed that German enterprises build up subsidiaries abroad or agree to other forms of cooperation. As a result, foreignness experiences are part of the everyday work for employees of internationally acting enterprises, because every day, common and across locations projects and tasks have to be mastered. Colleagues with different backgrounds are confronted with different patterns of orientation and have to manage challenges of intercultural situations (Pant \& Singh, 2001, p. 563). Most of the studies focus on expatriates; however, this topic does not only refer to this professional area. Just as often are employees affected by this who have to deal with international projects without being sent out abroad (Graf, 2004, p. 3).

Numerous studies in this field limit their analysis of such interaction processes to country-related cultural differences and deviate conclusions for the success of intercultural collaboration without referring to empirical evidence. Furthermore, often only a single aspect is being researched, so it is exclusive. Studies that research interaction problems with the help of monocausal explanation approaches remain unavoidable incomplete, because they neither consider further influence factors nor they investigate their interdependency. Concerning the study at hand, an extended understanding of culture is being assumed that legitimates a multiple explanation approach of influencing factors outside of country-related cultural frontiers (Welsch, 1999; Hansen, 2000; Bolten, 2004; Lösch, 2005; Bhabha, 2011). Considering this, two cultural influence factors for the success of intercultural collaboration are chosen and investigated: country culture (CC) and organizational culture (OC).

For the intercultural collaboration of employees of an international enterprise, particularly the national and the organizational level have to be distinguished from each other (Kumbruck \& Derboven, 2009, p. 25). Every employee learns a country-related cultural orientation system since birth, which is continuously enhanced due to life-long socialization processes. The thereby taught values and norms affect his/her thinking, attitudes and behavior and underlie a dynamical change process when interacting with others. After the entrance in an 
enterprise, an employee is additionally becoming part of a particular organizational culture, so that the interaction of influencing factors becomes more complex. In the focus of this study is the question how country related cultural and organization-related cultural aspects influence the success of intercultural collaboration between employees of an internationally acting enterprise being located in Germany and their colleagues from the subsidiaries located in Singapore and the USA and how the relationship of interdependency of the single influencing factors is arranged.

The for the investigation relevant constructs are being defined as follows:

Intercultural collaboration: Interaction and communication between social systems that either interact with each other face to face or with the help of other communication channels (König \& Schattenhofer, 2007, p. 15; Krentzel, 2001, p. 35). For the case at hand, this refers to colleagues of a German enterprise at its three subsidiaries in Germany (headquarter), Singapore and the USA (subcompanies).

Country-related culture: 'Culture is a big amount of people that belong to a nation via birth or who affiliate themselves to this culture, or having developed this culture during the process of their history and define this culture as being obligatory or as being crucial for their existence' (Cramer, 2007, p. 14; translated by the authors).

Organizational culture: 'Patterns of common basic assumptions that the group learned when having mastered its problems of external adaption and internal integration and that have proven themselves and thus count as being obligatory; and that thus are being passed to new members as a rationally and emotionally correct approach for the handling of these problems' (Schein, 1995, p. 25; translated by the authors).

Work satisfaction as an indicator for success of the intercultural collaboration: To engage work satisfaction as an indicator for success of the intercultural collaboration is being considered according to Stahl (1998), Brüch (2001), Krentzel (2001) Podsiadlowski (2002) and Cramer (2007), amongst others. Work satisfaction indicates 'to what extent individual needs, expectations and hopes are being fulfilled through the individual experience at the work place' (Krentzel, 2001, p. 94; translated by the authors).

\section{Question and Methodological Procedure}

The study at hand has its focus on intercultural collaboration that revealed itself as a complex phenomenon due to the numerous different influencing factors influencing the success of intercultural collaboration.

The investigation of influencing factors for the success of intercultural collaboration and their interdependency was conducted with the help of three steps. Step 1 was a detailed research of the literature to identify possible influences that emanate from the country-related culture and the organizational culture to the intercultural collaboration. A comparison of different studies however revealed that the particular influencing factors very differently affect - according to the particular context- intercultural interaction.

Due to the - from a scientific point of view - lacking knowledge referring to the object of the investigation at hand, problem-focused interviews with 26 probands have been conducted in step 2 to validate the relevance of the researched influencing factors for the context at hand and if necessary, to identify further non-considered factors. This procedure is in accordance with Kelle (2007, p. 54) who clearly argues for a previously and sensible limitation of the hypotheses to avoid an arbitrary generation of hypotheses that would lead to a falsification of the previously generated hypotheses. Regarding the country-related and organizational cultural dimensions, the following hypotheses have been generated:

There are bigger differences between the locations in Germany and Singapore than between the locations in Germany and the USA. The following significant differences are to be expected:

$H 1(L K)$ : Between the locations in Germany and Singapore, there are bigger country-related cultural differences than between the locations in Germany and the USA.

$H 2$ (UK): The organizational cultures do not significantly differ from each other referring to the three locations in Germany, Singapore and the USA.

H3: The intercultural collaboration between the subcompany in Singapore and the headquarter in Germany is expected to be more successful than the intercultural collaboration between the subcompany in the USA and the headquarter in Germany.

$H 4(L K)$ : There are country-related and organizational cultural influencing factors that positively influence the success of intercultural collaboration. The higher collectivism is shaped, the more successful is intercultural collaboration. 
H5 (UK): The higher the three organizational cultural dimensions of outcome-, career- and employee-orientation and work climate at the particular subcompanies are shaped, the more successful is the intercultural collaboration with the headquarter.

H6: Country-related and organizational cultural dimensions that have a positive influence on the success-potential are significantly higher shaped at the Singaporean location than at the US-American location.

H7: Between the country-related and the organizational culture, there is a significant mediator-effect, where the country-related culture functions as the predictor variable, organizational culture functions as the mediator variable and work satisfaction functions as the criterion variable.

With step 3, the hypotheses have been tested with the help of a quantitative measuring instrument (standardized online survey). For the country-related culture, the already validated measuring instrument of Triandis and Gelfand (1998) has been consulted, where the both scales of Individualism (IND) and Collectivism (KOL) are operationalized, each via 8 items. For the operationalization of organizational culture, the three dimensions outcome-and career-orientation (EKO, 7 items), employee-orientation (MAO, 7 items) and work climate (AK, 11 items) by Unterreitmeier (2004) have been used, whose validity could be proven with the help of a replication study (Unterreitmeier \& Schwinghammer, 2004, pp. 27-36). As the indicator for success of the intercultural collaboration, work satisfaction $(Z)$ has been chosen. The 8 items have been adopted by Podsiadlowski (2002) for the English and by Cramer (2007) for the German version of the survey. In both cases, a high reliability for this scale is indicated (Podsiadlowski, 2002, p. 213; Cramer, 2007, p. 196).

Overall, a combination of methods referring to qualitative and quantitative research steps has been used, whereas the qualitative investigation was used for the generation of hypotheses and the quantitative investigation was used for the testing of the hypotheses. To achieve a as high as possible construct equivalence of the quantitative measuring instrument, the back-translation- and the committee-approach of Brislin have been applied in a pilot study (Krentzel, 2001, p. 55). With the help of a Principal Component Analysis, furthermore the factorial structure of the 6 dimensions could be adequately confirmed. With the help of Cronbach's Alpha as an indicator of the internal consistency, adequate reliability values $(\alpha \geq .65)$ could have been achieved for all 6 scales and for the whole sample:

Table 1. Reliability of the quantitative measuring instrument of the study at hand

\begin{tabular}{lllll}
\hline \multirow{2}{*}{ Scale } & N & \multicolumn{3}{c}{ Cronbach's Alpha } \\
& Items & G & SIN & USA \\
\hline Work Satisfaction & 8 & .82 & .93 & .92 \\
Individualism & 8 & .73 & .80 & .67 \\
Collectivism & 8 & .67 & .83 & .83 \\
Outcome- and career-orientation & 7 & .70 & .78 & .78 \\
Employee-orientation & 7 & .86 & .92 & .92 \\
Work Climate & 11 & .88 & .80 & .83 \\
\hline
\end{tabular}

With the help of further tests (test for normal distribution, test for homoscedasticity of variances and covariances), all relevant conditions for the statistical procedures could have been ensured.

\section{Sample}

The sample of the study at hand consists of overall 282 employees of an internationally acting enterprise headquartered in Germany. The sample at the German location is 97, at the Singaporean location 77 and at the US-American location 108 people. The sociodemographic distribution of the probands is - after having subtracted the missing values - as follows: 92 probands are female (33\%), 187 probands are male (67\%). The average age of the whole sample is 43.6 years. With an age of 40.2 years, the probands at the Singaporean location are the youngest, followed by Germany (42.1 years) and the USA (47.4). Regarding the hierarchical levels, 133 employees (47\%) and 148 managers (53\%) have completed the survey. The sample is with regards to the sociodemographic data thus relatively balanced. A big strength on the conceptual level of this empirical investigation approach is that the data collection was not conducted in a laboratory context - which is often the case for research dealing with intercultural topics- but real interactions from practice have been analyzed. 


\section{Findings}

\subsection{Hypothesis 1 and 2}

To test for hypothesis 1 and 2, a cultural comparison analysis helped to identify between which locations significant mean value differences exist. For this, a single factor ANOVA was conducted for each case, as well as a post-hoc test according to the Scheffé-procedure. Because the scale of employee-orientation shows heteroscedasticity, a Welch-test was considered, too. For the scale of work climate, only an approximate normal distribution was identified, so that at this point, an H-test according to Kruskal and Wallis was applied. A Post-hoc-tests indicates, that a significant mean average with $\mathrm{p}=.000$ is only available between the German $(\mathrm{M}=5.33)$ and the Singaporean sample $(\mathrm{M}=5.90)$. The group pair Germany and the US does not reach a significant result with $\mathrm{p}=.058$ and $\alpha \leq .050$ for the dimension collectivism. Because of the grater cultural distances between the German and the Singaporean and the German and the American business locations, Hypothesis 1 is fully supported.

Table 2. Variance analyses with country-related and organizational cultural dimensions

\begin{tabular}{|c|c|c|c|c|c|c|c|c|c|}
\hline Dimension & Lo & cation & M & & $\mathrm{SD}$ & & $\mathrm{df}$ & $\mathrm{F}$ & $\mathrm{p}$ \\
\hline \multirow{2}{*}{ IND } & $\mathrm{D}$ & SIN & 4.70 & 4.70 & 0.81 & 0.97 & \multirow{2}{*}{$2 ; 268$} & \multirow{2}{*}{1.52} & .99 \\
\hline & & USA & & 4.51 & & 0.81 & & & .32 \\
\hline \multirow{2}{*}{$\mathrm{KOL}$} & $\mathrm{D}$ & $\mathrm{SIN}$ & 5.33 & 5.90 & 0.73 & 0.71 & \multirow{2}{*}{$2 ; 263$} & \multirow{2}{*}{10.34} & $.00^{*}$ \\
\hline & & USA & & 5.60 & & 0.86 & & & .06 \\
\hline \multirow{2}{*}{ EKO } & $\mathrm{D}$ & $\mathrm{SIN}$ & 4.40 & 4.81 & 0.88 & 0.95 & \multirow{2}{*}{$2 ; 261$} & \multirow{2}{*}{3.97} & $.03 *$ \\
\hline & & USA & & 4.48 & & 1.03 & & & .86 \\
\hline \multirow{2}{*}{ MAO } & $\mathrm{D}$ & SIN & 4.89 & 4.88 & 1.00 & 1.20 & \multirow{2}{*}{$2 ; 255$} & \multirow{2}{*}{1.92} & 1.00 \\
\hline & & USA & & 4.58 & & 1.37 & & & .23 \\
\hline \multirow{2}{*}{$\mathrm{AK}$} & $\mathrm{D}$ & SIN & 4.96 & 4.77 & 0.87 & 0.79 & \multirow{2}{*}{2} & \multirow{2}{*}{-} & \multirow{2}{*}{.26} \\
\hline & & USA & & 4.96 & & 0.95 & & & \\
\hline
\end{tabular}

* significant on a $5 \%$-level.

Table 2 shows that with $\mathrm{p}<.05$ only for the scales of collectivism and outcome- and career-orientation significant differences for the mean values between the two groups exist. The Post-hoc- tests according to the Scheffé-procedure show that the differences for the mean values only exist between German and the Singaporean sample (KOL: $\mathrm{p}=.00 ; \mathrm{M} D \mathrm{D}=5.33 ; \mathrm{M}$ _SIN=5.90/EKO: $\mathrm{p}=.03 ; \mathrm{M} \mathrm{D}=4.40 ;$ M_SIN=4.81). Hypothesis 1 is thus affirmed. Hypothesis 2 is falsified. Hence, greater significant differences for the mean values not only exist between German and Singaporean employees on the country-related, but also on the organizational cultural (H2) level than between German and US-American colleagues (H1).

\subsection{Hypothesis 3}

Hypothesis 3, for which the intercultural collaboration between German and Singaporean employees in spite of greater country-related cultural differences is expected to be more successful, was tested with the help of a T-test. The scale of work satisfaction was used here as an indicator for the success of the intercultural collaboration.

Table 2. T-test with the scale of work satisfaction as an indicator for success of the intercultural collaboration

\begin{tabular}{|c|c|c|c|c|c|}
\hline Dimension & M & SD & $\mathrm{df}$ & $\mathrm{T}$ & $\mathrm{p}$ \\
\hline Work Satisfaction G-SIN & 5.24 & 0.80 & \multirow{2}{*}{95} & \multirow{2}{*}{2.95} & \multirow{2}{*}{$.00 *$} \\
\hline Work Satisfaction G-USA & 5.20 & 0.79 & & & \\
\hline
\end{tabular}

* significant on a 5\%-Level.

Hypothesis 3 is affirmed. Although greater cultural difference exist between German employees and their colleagues in Singapore (see table 2), the intercultural collaboration is estimated to be more successful than with the colleagues from the US-American location (table 3: M_D-SIN=5.24; M_D-USA=5.20; $\mathrm{p}=.00$ ). With $\mathrm{p}=.004$ is the mean value for satisfaction with the cooperation between German and Singaporean coworkers $(\mathrm{M}=5.24)$ 
significantly higher than the mean value for the cooperation between German and American coworkers $(M=5.20)$. Therefore, the opinion of the cultural comparative research that greater cultural differences lead to more interaction problems (e.g. Stahl, 1998, p. 39; Ward et al., 2001, p. 9) thus cannot be affirmed. The analysis of further factors is thus crucial for the identification of possible synergy-potentials.

\subsection{Hypothesis 4 and 5}

To test for hypothesis 4 and 5, a regression was conducted, with country-related and organizational cultural dimensions as independent variables and work satisfaction as an indicator for the success of the intercultural collaboration as a dependent variable. Due to the multicollinearity between the three organizational cultural dimensions, they have been separately included in a model:

Table 3. Regression analysis with country-related- and organizational cultural dimensions

\begin{tabular}{|c|c|c|c|c|}
\hline \multirow[t]{2}{*}{ Dimension } & \multicolumn{4}{|c|}{$\begin{array}{l}\text { Work Satisfaction as an indicator for success of the intercultural } \\
\text { collaboration }\end{array}$} \\
\hline & $\mathrm{R}^{2}$ & $\beta$ & SE & $\mathrm{p}$ \\
\hline IND & & -0.04 & & .50 \\
\hline KOL & 0.06 & 0.23 & 1.01 & $.00 *$ \\
\hline EKO & 0.19 & 0.44 & 0.93 & $.00^{*}$ \\
\hline MAO & 0.37 & 0.61 & 0.81 & $.00 *$ \\
\hline $\mathrm{AK}$ & 0.43 & 0.66 & 0.78 & $.00 *$ \\
\hline
\end{tabular}

* significant on a $5 \%$-level.

Table 4 shows that when regarding the country - related cultural scales, only the dimension of collectivism $(\beta=0.23 ; \mathrm{p}=.00)$ explains work satisfaction, but not the dimension of individualism $(\mathrm{p}=.50)$. Relating to organizational culture, all three dimensions can be seen as an indicator for success of intercultural collaboration in connection to work satisfaction. Both, outcome- and career-orientation, as well as employee-orientation and work climate thus can be understood as influencing factors that positively influence the interaction between culturally foreign colleagues when highly shaped (EKO: $\beta=0.44 ; p=.00 / \mathrm{MAO}: \beta=0.61 ; p=.00 / \mathrm{AK}$ : $\beta=0.66$; $\mathrm{p}=.00)$. Thus, the assumption from the qualitative survey $(\mathrm{H} 4)$ that country-related and organizational cultural factors positively influence the success of intercultural collaboration can be affirmed. Furthermore, culture dimensions $(\mathrm{p}=.496)$ are no predictor for higher success in intercultural teamwork. Therefore, the independent variable collectivism can predict the dependent variable satisfaction with a significance level of $p=000$. The standardized regression coefficient .233 indicates, that the intercultural teamwork is evaluated more successfully, the higher the collectivistic expression. There are no different expectations between cultures.

\subsection{Hypothesis 6}

Furthermore, Hypothesis 6 was investigated and thus also the greater success of intercultural collaboration between German and Singaporean colleagues that is measured with the help of the scale of work satisfaction. For this, for all scales with success-promoting potential (see Table 4: KOL, EKO, MAO, AK) comparisons of mean values between the Singaporean and American sample were conducted:

Table 4. Mean values of the Singaporean and the American sample for the scales with success-promoting potential

\begin{tabular}{llllllll}
\hline \multirow{2}{*}{ Dimension } & M & \multicolumn{5}{c}{ SD } & \multicolumn{2}{l}{ df } & T & $\mathrm{p}$ \\
& SIN & USA & SIN & USA & & & \\
\hline KOL & 5.90 & 5.60 & 0.71 & 0.86 & 172 & 2.39 & $.02 *$ \\
EKO & 4.81 & 4.48 & 0.95 & 1.03 & 172 & 2.18 & $.03 *$ \\
MAO & 4.88 & 4.58 & 1.20 & 1.37 & 168 & 1.45 & .15 \\
AK & 4.77 & 4.96 & 0.79 & 0.95 & 170 & -1.32 & .19 \\
\hline
\end{tabular}

* significant on a $5 \%$-level.

Table 5 leads to the conclusion that only between the both dimensions of collectivism $(p=.02)$ and outcome- and career-orientation $(\mathrm{p}=.03)$ significant differences in the mean values exist. When regarding the mean values, it 
becomes obvious that the particular values at the Singaporean location are higher shaped than at the American location (KOL: M_SIN=5.90; M_USA=5.60 / EKO: M_SIN=4.81; M_USA=4.48). These correspond in both cases to the high shapes of the dimensions, for which-according to table 4- a success-promoting potential could be analyzed. Thus, these two provide a hint that a higher shaped collectivism and a higher shaped outcome- and career-orientation influence the greater success of the intercultural collaboration. Because only two of the four cultural dimensions show a significant difference in mean values, hypothesis 4 can only be partially affirmed.

\subsection{Hypothesis 7}

To be able to investigate the interdependency of the two dimensions in relation to the success of intercultural collaboration (H7), mediator-analyses have been conducted for the German-Singaporean and the German-American sample. On the basis of theoretical considerations, (Kremmel, 1996, amongst others) and the findings from the qualitative survey, the dimension of collectivism was used as the predictor variable, outcomeand career-orientation as the mediator-variable and work satisfaction as the indicator for success of the intercultural collaboration as the criterion variable in the mediator model. In the case of a partial mediation, the predictor variable directly influences the criterion variable (c) which is not completely nullified by the mediator variable, but only reduced $\left(\mathrm{c}^{\prime}\right)$. When the direct effect (c) under statistical control of the mediator is intervened $\left(\mathrm{c}^{\prime}\right)$, that is totally becoming non-significant, a total mediator-effect is existent (Urban \& Mayerl, 2007, p. 10). The significance of the indirect effect is calculated with the help of the Sobel-test (Urban \& Mayerl, 2007, p. 6 ff.)

Table 5. Mediator analysis for the measurement of the indirect influence of the organizational culture

\begin{tabular}{|c|c|c|c|c|c|c|}
\hline \multirow{3}{*}{ Path (Dimension) } & & & & & & \\
\hline & \multicolumn{3}{|c|}{ Germany-Singapore } & \multicolumn{3}{|c|}{ Germany-USA } \\
\hline & \multirow{2}{*}{$\begin{array}{l}\beta \\
0.21\end{array}$} & \multirow{2}{*}{$\frac{\mathrm{SE}}{0.90}$} & \multirow{2}{*}{$\frac{\mathrm{p}}{.01^{*}}$} & \multirow{2}{*}{$\frac{\beta}{0.29}$} & \multirow{2}{*}{$\frac{\mathrm{SE}}{0.97}$} & \multirow{2}{*}{$\frac{\mathrm{p}}{.00^{*}}$} \\
\hline (KOL-Z) & & & & & & \\
\hline (KOL-EKO) & 0.23 & 0.91 & $.00 *$ & 0.24 & 0.94 & $.00^{*}$ \\
\hline (EKO-Z) & 0.38 & 0.84 & $.00 *$ & 0.50 & 0.89 & $.00 *$ \\
\hline $\mathrm{c}^{\prime} \quad(\mathrm{KOL}-\mathrm{Z})$ & 0.12 & 0.84 & .11 & 0.18 & 0.87 & $.00^{*}$ \\
\hline Sobel-Test & $.01 *$ & & & $.00 *$ & & \\
\hline
\end{tabular}

* significant on a $5 \%$-level.

The results from the Sobel-test in table 6 show that in both cases, a significant indirect effect emanates from the organizational culture (D-SIN: $p=.01 / \mathrm{D}-\mathrm{USA}: \mathrm{p}=.00$ ) and thus hypothesis 5 is verified. While for the German-Singaporean sample a total mediator effect is existent, only a partial indirect effect can be observed for the German-American sample. Hence, in the interaction with Singaporean colleagues, the direct effect of the country-related culture on the success (Path $\mathrm{c}: \beta=0.21 ; \mathrm{p}=.01$ ) of the intercultural collaboration is lost, so that country-related cultural differences get into the background in favor of a commonly lived organizational culture (Path $c^{\prime}: \beta=0.12 ; p=.11$ ). From this, a further reason for the greater success of the German-Singaporean collaboration can be deviated. Regarding the German-American interaction, the country-related cultural dimension (Path $\mathrm{c}$ : $\beta=0.29 ; \mathrm{p}=.00$ ) keeps its significant influence under the control of the mediator (Path $\mathrm{c}^{\prime}$ : $\beta=0.18 ; \mathrm{p}=.00)$.

Hence, the organizational culture in the case of the German-American collaboration is not an effective management tool to improve the success of intercultural collaboration. Accordingly, measures become important which improve the mutual comprehension and help to learn the cultural foreign orientation system. Obviously, the significant lower collectivism of the USA (Table 5) is connected to the fact that a low willingness to adopt organizational cultural values is predominant. Accordingly, the German headquarter should promote an increase of the internalization power of the organizational culture at the US-American location.

\section{Discussion}

As a central result, it could be found that the cultural differences on the country-related and organizational level between German and Singaporean colleagues are indeed greater than between German and American employees (H1), but these do not lead- in contrast to the general opinion of the cultural comparative management researchto a worse intercultural collaboration (H3).

The results from Hypothesis 1 are in two ways very interesting. First, a significant mean value was found between the German and the Singaporean sample only for the dimension collectivism, as well in the horizontal 
as in the vertical manifestation. Dimension individualism shows no significant mean values. In contrast to the US sample, the Singaporean sample shows in higher collectivist manifestation. Whereas horizontal collectivism focusses on cooperative behavior towards colleagues, vertical collectivism focusses on the evaluation within family.

Findings indicate that the Singaporean sample also shows individualistic tendencies. The mean values from the German ( $M=4.70)$, Singaporean $(M=4.70)$ and the US sample $(M=4.51)$ showed similar characteristics and do not differentiate significantly $(\mathrm{p}=.221)$. This indicates that the Country-related culture regarding the dimension individualism in Singapore has changed significantly.

Positive effects for the intercultural collaboration could be proven for the scales of collectivism, outcome- and career-orientation, employee-orientation and work climate (H4 and H5). After a further analysis of the data, especially at the Singaporean location, a higher shaped collectivism (country-related culture), as well as a higher success- and career-orientation (organizational culture) as indicators for the greater success of the German-Singaporean collaboration could be proven, too (H6).

The mediator analysis, for which organizational culture was used as the mediator variable, was able to provide further information about the interdependency of the single variables (H7). The total mediation in the German-Singaporean sample due to the organizational culture leads to the fact that the fulfillment of organizational cultural functions is of especially high importance. Thus the relevance of organizational culture is increased, which can be understood as an effective management tool. As a practical implication for the German-American collaboration, in contrast, the importance of the country-related culture has to be emphasized. Here it would be sensible to increase the internalization power of the organizational culture, which could be realized with the help of intercultural projects. Simultaneously, the mutual comprehension could be improved and the motivation to adopt organizational cultural values could be increased, too.

Finally, it can be concluded that a mono-causal approach is not adequate when researching intercultural collaboration. With the help of detailed investigations about different country-related and organizational cultural dimensions it could have been shown, how complex intercultural collaboration is. Country-related and organizational cultural differences are only a problem when a missing understanding about the interdependency of the influencing factors is given. When this is the case, an enterprise can use targeted measures and context-specific methods of resolution to improve intercultural collaboration.

\section{References}

Bhabha, H. K. (2011). Die Verortung der Kultur [The contextualisation of culture]. Tübingen: Stauffenburg-Verlag.

Bolten, J. (2004). Interkulturelles Handeln in der Wirtschaft. Positionen, Modelle, Perspektiven, Projekte [Intercultural acting in business. Positions, models and perspectives]. Sternenfels: Verlag Wissenschaft \& Praxis.

Brüch, A. (1998). Individualismus-Kollektivismus als Einflussfaktor in interkulturellen Kooperationen [Individualism-collectivism as influence factor in intercultural cooperations]. In E. Spieß (Ed.), Formen der Kooperation. Bedingungen und Perspektiven [Shapes of cooperation. Conditions and perspectives] ( $\mathrm{p}$. 177-192). Göttingen: Hogrefe-Verlag.

Cramer, T. (2007). Interkulturelle Zusammenarbeit in multinationalen Teams [Intercultural collaboration in multinational teams]. München: GRIN Verlag.

Graf, A. (2004). Interkulturelle Kompetenzen im Human Resource Management. Empirische Analyse konzeptioneller Grundfragen und der betrieblichen Relevanz [Intercultural competences for Human Resource Management. An empirical analysis of conceptional questions and of organizational relevance]. Wiesbaden: Deutscher Universitäts-Verlag.

Hansen, K. P. (2000). Kultur und Kulturwissenschaft. Eine Einführung [Culture and Culture Science. An introduction] (2nd ed.). Tübingen: Francke Verlag.

Kelle, U. (2007). Integration qualitativer und quantitativer Methoden [Integration of qualitative and quantitative methods]. In U. Kuckartz \& H. Dresing Thorsten Grunenberg (Eds.), Qualitative Datenanalyse: computergestützt. Methodische Hintergründe und Beispiele aus der Forschungspraxis [Qualitative data analysis: computer supported. Methodoligocal background and examples of research practice] (2nd ed., p. 50-64). Wiesbaden: VS Verlag für Sozialwissenschaften. 
König, O., \& Schattenhofer, K. (2007). Einführung in die Gruppendynamik [Introduction to group dynamics] (2nd ed.). Heidelberg: Carl-Auer-Systeme.

Kremmel, D. (1996). Das Verhältnis zwischen Unternehmensstrategie und Unternehmenskultur unter besonderer Berücksichtigung des organisationalen Lernens [The relationship between organizational strategy and culture under the special consideration of organisational learning]. Hallstadt: Rosch-Buch.

Krentzel, G. A. (2001). Multinationale Arbeitsgruppen. Implikationen für die Führung [Multinational work teams. Implications for leadership]. Wiesbaden: Deutscher Universitäts-Verlag.

Kumbruck, C., \& Derboven, W. (2009). Interkulturelles Training. Trainingsmanual zur Förderung interkultureller Kompetenzen in der Arbeit [Intercultural training. Training manual for the promotion of intercultural competence for work] (2nd ed.). Heidelberg: Springer-Verlag.

Lösch, K. (2005). Begriff und Phänomen der Transdifferenz. Zur Infragestellung binärer Differenzkonstrukte [Concept and phenomenon of transdifference. Challening binary difference constructs]. In L. Allolio-Näcke (Ed.), Differenzen anders denken. Bausteine zu einer Kulturtheorie der Transdifferenz [Thinking different about differences. Aspects for a culture theory of transdifference] (pp. 26-52). Frankfurt: Campus-Verlag.

Pant, N., \& Singh, K. (2001). In Diversity is There Strength? Ruminations on Changing Faces in Business. In C. L. Cooper et al. (Eds.), The International Handbook of Organizational Culture and Climate (pp. 557-572). Chichester: John Wiley \& Sons.

Podsiadlowski, A. (2002). Multikulturelle Arbeitsgruppen in Unternehmen. Bedingungen für erfolgreiche Zusammenarbeit am Beispiel deutscher Unternehmen in Südostasien [Multicultural work groups in organizations. Conditions for the successful collaboration under the example of German organizations in South East Asia]. Münster: Waxmann Verlag.

Schein, E. H. (1995). Unternehmenskultur. Ein Handbuch für Führungskräfte [Organizational culture. A handbook for leaders]. Frankfurt: Campus-Verlag.

Stahl, G. K. (1998). Internationaler Einsatz von Führungskräften [International assignment of leaders]. München: Oldenbourg Verlag.

Triandis, H. C., \& Gelfand, M. J. (1998). Converging Measurement of Horizontal and Vertical Individualism and Collectivism. Journal of Personality and Social Psychology, 74(1), 118-128.

Unterreitmeier, A. (2004). Unternehmenskultur bei Mergers \& Acquisitions. Ansätze zu Konzeptualisierung und Operationalisierung [Organizational culture during Mergers \& Acquisitions.Approaches for the conceptualisation and operationalisation]. München/Wiesbaden: Deutscher Universitäts-Verlag.

Unterreitmeier, A., \& Schwinghammer, F. (2004). Die Operationalisierung von Unternehmenskultur Validierung eines Messinstruments [The operationalisation of organizational culture - Validation of a measuring instrument]. München: Ludwig-Maximilians-Universität.

Urban, D., \& Mayerl, J. (2007). Mediator-Effekte in der Regressionsanalyse [Mediator-effects of regression analysis]. Universität $\quad$ Stuttgart. $\quad$ Retrived http://www.uni-stuttgart.de/soz/soziologie/regression/Mediator-Effektev1-3.pdf

Ward et al. (2001). The Psychology of Culture Shock (2nd ed.). Hove: Routledge.

Welsch, W. (1999). Transculturality. The Puzzling form of Cultures Today. In M. Featherstone (Ed.), Spaces of Culture (pp. 194-213). London: Sage Publications.

\section{Copyrights}

Copyright for this article is retained by the author(s), with first publication rights granted to the journal.

This is an open-access article distributed under the terms and conditions of the Creative Commons Attribution license (http://creativecommons.org/licenses/by/3.0/). 